\title{
Effect of larval crowding on the life history traits of Sesamia nonagrioides (Lepidoptera: Noctuidae)
}

\author{
Argyro A. FANTINOU ${ }^{1}$, Dionyssios C. PERDIKIS ${ }^{2}$ and Nikolaos STAMOGIANNIS ${ }^{1}$ \\ ${ }^{1}$ Laboratory of Ecology and Environmental Sciences, Agricultural University of Athens, Iera Odos 75, 11855 Athens, Greece; \\ e-mail: argyr@aua.gr \\ ${ }^{2}$ Laboratory of Agricultural Zoology and Entomology, Agricultural University of Athens, Iera Odos 75, 11855 Athens, Greece
}

Key words. Lepidoptera, Noctuidae, Sesamia nonagriodes, density, competition, development, fecundity, pink stalk borer

\begin{abstract}
This study determined the effect of larval density-dependent competition for food on development and adult fitness in Sesamia nonagriodes Lef. (Lepidoptera: Noctuidae). Different numbers (5, 10, 15, 20 and 30 individuals) of larvae of the pink stalk borer were reared on a constant amount of food. Although crowding during the immature stages did not significantly increase mortality, it prolonged the larval developmental period and resulted in reduced pupal weight. Females were more adversely affected by high density than males, resulting in lighter females, indicating that female growth is more sensitive to density. The fecundity of the adults reared in the various larval crowding treatments was analysed. Total female fecundity was correlated negatively with increasing larval density. The effects of crowding on fecundity were not caused by the reduced pupal weight, indicating that food shortage during larval development may affect adult traits. Female longevity was negatively affected by density and positively related to pupal weight. Thus, larval density may affect the allocation of food resources and adult fitness. We conclude that crowding related changes during larval development directly affect larval life and reduce female fitness.
\end{abstract}

\section{INTRODUCTION}

Intraspecific competition for food resources can be an important factor affecting the development and adult characteristics of organisms. A reduced availability of food due to crowding during development can affect adult behaviour and fitness (Marshall, 1990; Mueller, 1997; Hirschberger, 1999). In insects, in particular, crowding affects their morphology, behaviour and physiology (Klomp, 1964; Barbosa \& Peters, 1970; Bradshaw \& Holzapfel, 1989; Denno \& Roderick, 1992; Denno et al., 1995; Rhainds et al., 2002).

Larvae of several insect orders aggregate, during development in order to feed completely enclosed within host plant tissues. Although this feeding habit helps to protect the immatures from predators and extremes of temperature, it can also increase competition. As more conspecifics compete for resources, the population density may cause behavioural and developmental changes. These changes, which affect development and reproduction, are recorded in several studies in which larval density and food availability was varied (Leonard, 1968; Amezaga \& Garbisu, 2000; Shafiei et al., 2001).

Female reproduction in the order Lepidoptera relies primarily on reserves accumulated during the larval stage, since adults have little opportunity to accumulate additional resources. Shortage of food during the larval stage may constrain the feeding rate, utilization and allocation of food. Thus, the final size of an insect is often determined by larval population density, which determines the final larval size. Hence, competition for food among larvae that develop at different densities affects pupal size and fecundity (Jones et al., 1982; Honěk, 1993; Tammaru et al., 1996). Numerous studies on the effects of the stress of larval crowding have demonstrated both direct and indirect effects on the performance of Lepidoptera. The most obvious are the direct effects of a low survival rate, prolonged larval period and low pupal weight (Mercer, 1999; Tammaru et al., 2000; Gibbs et al., 2004; Bauerfeind \& Fischer, 2005). Rearing larvae in overcrowded conditions are linked indirectly with adult fitness, specifically small adult size, reduced fecundity and lowperforming offspring (Quring \& McNeil, 1984; Boggs, 1997; Fisher \& Fiedler, 2001).

The Mediterranean Basin Sesamia nonagrioides Lef., commonly known as the pink stalk borer, is one of the most important pests, causing severe damage, particularly to the late corn crop (Baniabassi, 1981; Tsitsipis, 1990). This insect is multivoltine and completes 3-4 generations annually. Larvae diapause from the end of August until January, after which they remain in a post-diapause state (Fantinou et al., 1995, 1998), with the first adults appearing at the beginning of April in Greece (Tsitsipis, 1990). Adult life lasts 5-10 days, with the smaller males emerging slightly earlier than females (Al Salti, 1984; Babilis \& Mazomenos, 1992; Lopez et al., 2003). Females never fly before mating, do not display any overt response to males and are attractive to males as early as the first scotophase after emergence (Lopez et al., 2003). Females lay their eggs in clutches of from a few to over 100 eggs under a leaf sheath and the larvae burrow into the stem where they live gregariously (Tsitsipis, 1990). Although one larva may occupy each root, several larvae may be found in a stem (Gillyboeuf et al., 1994; Cordero et al., 1998; Burton et al., 1999). A three-year study on Bt corn revealed that only mature larvae disperse in signifi- 
cant numbers from an infested plant (Eizaguirre et al., 2004). The percentage of larvae that disperse is dependent on the larval densities in the stems. Crowded larvae provided with food ad libitum have a high pupation rate, but the pupal weight of both sexes is significantly reduced at high larval densities (Fantinou \& Tsitsipis, 1999). However, the pupal developmental period was not affected by larval density. To our knowledge there are no studies on the effects of larval crowding on the reproductive traits of this insect.

This study was therefore undertaken to explore the effects of larval overcrowding on development and adult fitness, and the occurrence of trade-offs among the life traits. Our main objectives were to determine whether larvae developing at various densities and provided with the same amount of food differ in survival, larval development and sex ratio. We also examined whether any of these differences affected adult fitness, in particular fecundity.

\section{MATERIALS AND METHODS}

The $S$. nonagrioides culture used in this study originated from larvae collected from corn plants growing in fields around Kopais (Central Greece) in 2004. The details of the rearing procedures are provided in Fantinou et al. (1995). For the investigation on the effects of crowding on larval development and pupal traits, eggs were collected and kept at $25^{\circ} \mathrm{C}, 16 \mathrm{~L}: 8 \mathrm{D}$ and $60 \%$ $\mathrm{RH}$. Upon hatching larvae were transferred to plastic boxes (15 $\times 8 \times 3 \mathrm{~cm})$ and assigned to one of five density groups. The same amount of rearing medium (50 g) (Tsitsipis, 1984) was placed in each box. This is the optimal quantity for food for rearing $\sim 15$ individuals in terms of successful larval development and pupation, and this amount was used in several previous studies (Fantinou et al., 1995, 1998, 2004). The five density groups were: 5, 10, 15, 20 and 30 individuals per box. Four replicates of each density were used. Therefore in each box (replicate), regardless the different number of individuals (treatment), larvae had access to the same quantity of food. Every week, larvae from each box were transferred to new boxes with $50 \mathrm{~g}$ of fresh food and larval survival was checked every other day. The pupae were removed from each box immediately they developed, because of larval cannibalism (A.F. \& D.P., unpubl. data). Developmental larval period, pupation success, pupal weight and sex were recorded. The pupal weight of both sexes was measured one day after formation using an electronic balance accurate to $0.1 \mathrm{mg}$.

Oviposition of the moths that developed from the larvae at each of the five densities was compared. Ten females from each density constituted a replicate. In addition, pupae of similar weight reared at each of the densities were collected in order to determine the fecundity of the adults that emerged. Newly emerged females $(<24 \mathrm{~h})$ were individually placed in small wooden cages $(15 \mathrm{~cm} \times 15 \mathrm{~cm} \times 15 \mathrm{~cm})$, which were covered with a wire screen and had a side opening for introducing the adults and food. Each cage contained a small vial with two corn stems and cotton wool dipped in $10 \%$ sucrose solution. Females were allowed to mate with males from the colony. The cages were checked daily for eggs and dead moths. Corn stems were removed daily and number of eggs recorded. The total number of eggs laid by each female was recorded.

The data on larval mortality at the different population densities were analyzed by one-way ANOVA after being square-root transformed. Larval developmental period and pupal weight were analyzed using two-way ANOVA, with factors the density
TABLE 1. Effect of larval density on the larval and pupal traits (mean $\pm \mathrm{SE}$ ) of $S$. nonagrioides.

\begin{tabular}{cccc}
\hline $\begin{array}{c}\text { Density } \\
\text { larvae/box }(\text { mean* } \pm \text { SE) }\end{array}$ & $\begin{array}{c}\text { Mortality (\%) Larval period (days) } \\
(\text { mean* } \pm \text { SE) }\end{array}$ & $\begin{array}{c}\text { Pupal weight }(\mathrm{mg}) \\
\text { (mean* } \pm \mathrm{SE})\end{array}$ \\
\hline 5 & $15.00 \pm 9.57$ & $30.18 \pm 0.58$ & $214.39 \pm 11.18$ \\
10 & $10.00 \pm 4.08$ & $32.98 \pm 0.32$ & $187.08 \pm 5.59$ \\
15 & $15.03 \pm 3.18$ & $34.04 \pm 0.35$ & $182.76 \pm 5.63$ \\
20 & $8.75 \pm 2.39$ & $34.03 \pm 0.27$ & $180.43 \pm 4.07$ \\
30 & $32.50 \pm 13.14$ & $35.00 \pm 0.33$ & $166.68 \pm 3.99$ \\
\hline
\end{tabular}

* Values are the means of four replicates at each density.

and sex. In the analyses, replicates of the average value for development or weight per box and sex were used. The sex ratio $(q /(\delta+q)$ of the adults emerging in each box was analysed using one-way ANOVA, with factor the density. Because fecundity is correlated with pupal weight in many species, the lifetime fecundity was analysed as a function of crowding treatment in an ANCOVA with egg load per female as a response variable, density as an explanatory variable and pupal weight as a co-variate. Longevity of females was analysed by one-way ANOVA, with factor the larval density. The relationships among female longevity and larval developmental period, pupal weight and egg load were investigated using linear regression. In all cases the data were Box-Cox transformed prior to the analysis. Means were separated using the LSD test $(\alpha=0.05)$. Statistical analyses were conducted using the statistical package JMP (SAS Institute, 2005).

\section{RESULTS}

The rearing density of the larvae of $S$. nonagrioides affected the larval developmental period and pupal weight (Table 1). Cannibalism was not recorded in any of the treatments. Although larval survival was highest at the lowest density, crowding did not have a significant effect on survival to pupation $\left(\mathrm{F}_{4,15}=1.25, P>0.33\right)$, and there was no effect of density on the sex ratio of the pupae $\left(\mathrm{F}_{4,15}=0.267, P>0.894\right)$.

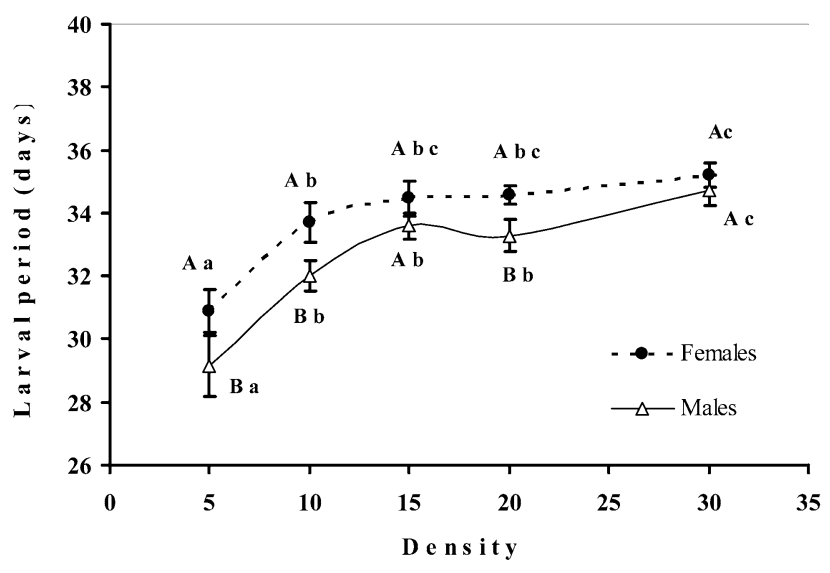

Fig. 1. Effect of $S$. nonagrioides larval rearing-density on sex specific larval-pupal developmental time when reared at $25^{\circ} \mathrm{C}$ and a photoperiod of $16 \mathrm{~L}: 8 \mathrm{D}$. Each point is the mean \pm SE of four replicates. Means for the two sexes followed by the same capital letter are not significantly different between. Means followed by the same lower case letter in each row are not significantly different (LSD test, $\alpha=0.05$ ). 


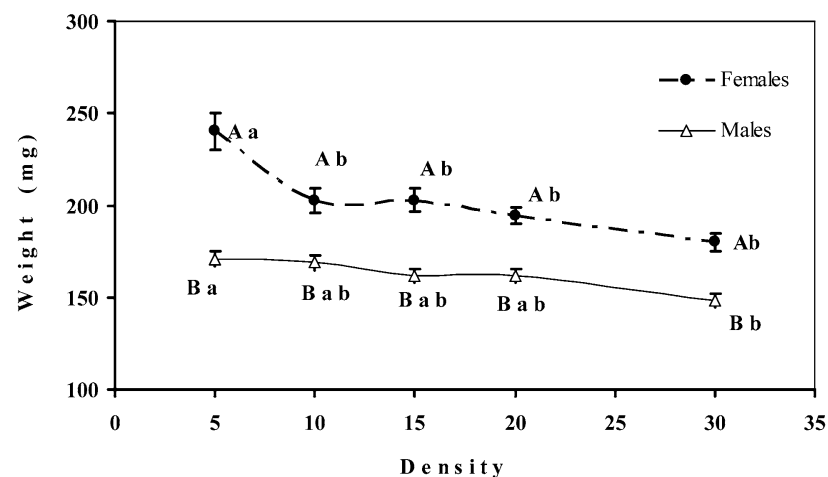

Fig. 2. Effect of $S$. nonagrioides larval rearing-density on sex specific pupal weight when reared under $25^{\circ} \mathrm{C}$ and a photoperiod of $16 \mathrm{~L}: 8 \mathrm{D}$. Each point represents the mean $\pm \mathrm{SE}$ of four replicates. Means for the two sexes followed by the same capital letter are not significantly different. Means followed by the same lower case letter in each row are not significantly different (LSD test, $\alpha=0.05$ ).

Increased density prolonged larval developmental time. There was a significant overall effect of larval density on the duration of larval development $\left(\mathrm{F}_{4,30}=19.69, P<\right.$ $0.0001)$, as well as a significant effect on sex ratio $\left(\mathrm{F}_{1,30}=\right.$ 6.907, $P<0.013$ ), but their interaction was not significant $\left(\mathrm{F}_{4,30}=0.76, P>0.556\right)$. In females, there were no significant differences at the intermediate densities in the duration of larval development, and males showed a significant increase in larval duration at the highest density (Fig. 1).

Pupal weight varied according to sex (Fig. 2). Females weighed significantly more than males at all densities $\left(\mathrm{F}_{1,30}=79.221, P<0.001\right)$. In addition, larval crowding reduced pupal weight $\left(\mathrm{F}_{4,30}=5.413, P<0.002\right)$, but there was no change in the sex ratio $\left(\mathrm{F}_{4,30}=0.892, P>0.480\right)$. Female pupae from larvae reared at densities higher than 10 individuals per box were significantly lighter in weight than those reared at 5 per box. However, the decrease in female weight between densities of 10 and 30 larvae per box was not significant. In males, a significant difference in weight between the different groups was seen only between the lowest and the highest densities (Fig. 2).

The number of eggs laid by the females of $S$. nonagrioides correlated positively with their pupal weight $(\mathrm{y}=$ $\left.184.33+5.73 \mathrm{x}, \mathrm{r}^{2}=0.24, \mathrm{~F}_{1,48}=15.45, P<0.001\right)$ and negatively with larval development time $(\mathrm{y}=35.73$

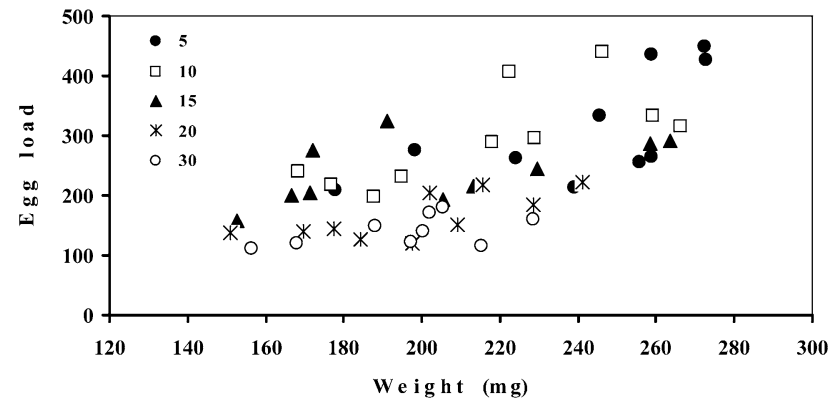

Fig. 3. Interactions between larval density, pupal weight and fecundity per female in $S$. nonagrioides.

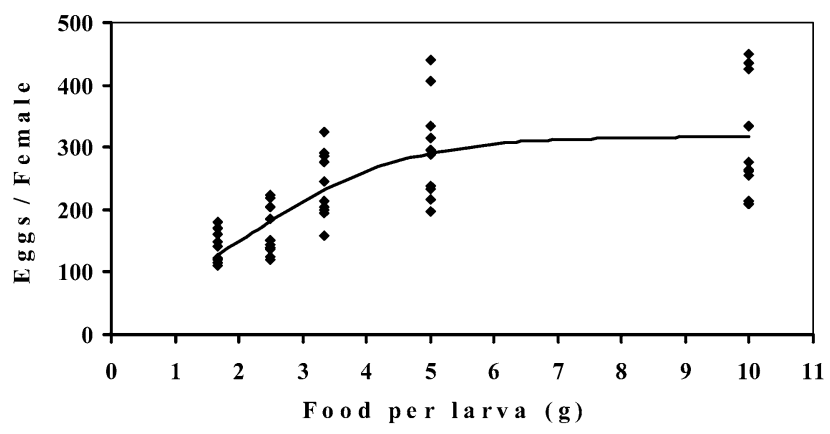

Fig. 4. Effect of larval food availability on female fecundity in $S$. nonagrioides.

$\left.-0.47 \mathrm{x}, \mathrm{r}^{2}=0.32, \mathrm{~F}_{1,48}=22.65, P<0.001\right)$. The relationship between pupal weight and fecundity for females reared at all the densities is presented in Fig. 3. The ANCOVA results of the effect of density on the number of eggs laid by the females, which used pupal weight as the covariate, showed that there was a significant effect of density $\left(\mathrm{F}_{4,44}=10.92, P<0.001\right)$. This indicated that the effect of density on the number of eggs laid by the females was not mediated by female weight. Therefore, it is clear that the negative effect of crowding on fecundity was confined mostly to females that were exposed to crowded conditions as larvae.

In an effort to further explore the possible effects of larval food shortage on adult traits, we analysed the various parameters of food quantity. When the quantity of food provided was divided by the number of larvae in each density group the correlation between food per larva and female development was found to be negative ( $\mathrm{y}=$ 35.99-0.49x, $\left.\mathrm{R}^{2}=0.17, \mathrm{~F}_{1,144}=28.88, P<0.001\right)$, and that between food per larva and female pupal weight was positive $\left(\mathrm{y}=173.54+6.69 \mathrm{x}, \mathrm{R}^{2}=0.17, \mathrm{~F}_{1,144}=29.14, P<\right.$ $0.001)$. Only the relationship between food per larva and development was significant for the males $(\mathrm{y}=$ $\left.35.47-0.65 \mathrm{x}, \mathrm{R}^{2}=0.21, \mathrm{~F}_{1,111}=29.74, P<0.001\right)$. In Fig. 4 the relationship between the number of eggs laid per female and the food per larva is given. This relationship is well described by the non-linear relationship: $\mathrm{Y}=\frac{K}{1+\exp (a-r x)}$, where $\mathrm{Y}$ is the fecundity and $x$ is the amount of food per larva $\left(\mathrm{R}^{2}=0.56, \mathrm{df}=47 ; \mathrm{K}=317.267\right.$

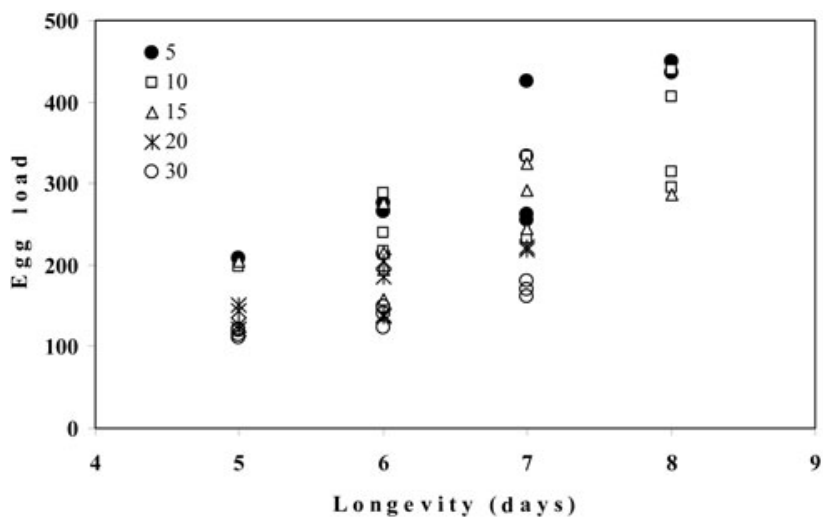

Fig. 5. Interactions between larval density, female longevity and female fecundity in $S$. nonagrioides. 
$\pm 18.991, \mathrm{t}=16.708, \mathrm{P}<0.001 ; \mathrm{a}=1.778 \pm 0.546, \mathrm{t}=$ $3.257, \mathrm{P}<0.002 ; \mathrm{r}=0.835 \pm 0.238, \mathrm{t}=3.502, \mathrm{P}<0.001)$. The longevity of female adults reared at different larval densities differed $\left(\mathrm{F}_{4,45}=2.70, P<0.042\right)$ and correlated positively with pupal weight and fecundity $(\mathrm{y}=55.78+$ $24.33 \mathrm{x}, \mathrm{r}^{2}=0.47, \mathrm{~F}_{1,48}=43.13, P<0.001$ and $\mathrm{y}=-223.18$ $+71.56 \mathrm{x}, \mathrm{r}^{2}=0.58, \mathrm{~F}_{1,48}=65.74, P<0.001$, respectively). However, it was unrelated to larval development time $\left(\mathrm{F}_{1,48}=0.35, P>0.34\right)$. In Fig. 5 the relationship between longevity and fecundity for females reared at different densities is presented.

\section{DISCUSSION}

Larval crowding was found to have a large impact on the fitness of larvae of $S$. nonagrioides through its effects on development and weight (Table 1, Fig. 1). The sexes have a similar developmental strategy, but weight acquisition was affected differently in the two groups, with females more sensitive to food shortage (Figs 1, 2). This suggests that crowded larvae grow for longer in order to overcome the consequences of competition and achieve a large size at metamorphosis. Nevertheless, larval development time is not longer even when food availability is low (Fig. 1). This could be related to the lower probability of survival under conditions of low food availability, as indicated by the increase in larval mortality rates at the highest density (Table 1), which affects both sexes equally. Under conditions of restricted food supply, many lepidopteran larvae extend their development and consequently their feeding period in order to attain a critical size for metamorphosis (Fischer \& Fiedler, 2001; Bauerfeind \& Fischer, 2005). In addition, larval crowding during development causes a reduction in female pupal and adult weight in a number of species (Leonard, 1968; Peters \& Barbosa, 1977; Fisher \& Fiedler, 2001; Agnew et al., 2002; Gibbs et al., 2004). However, the results of these studies are contradictory, so it is unclear whether these effects are caused by the group density per se or by the reduced availability of food. In Pararge aegeria (L.) for example, high larval crowding resulted in lower survival and a longer developmental period (Gibbs et al., 2004). Tammaru et al. (2000) found that crowding during early larval development strongly delayed larval growth in Epirrita autumnata and reduced pupal weight. On the contrary, high larval density caused Porthetria dispar (L.) larvae to develop faster with additional instars (Leonard, 1968). Bauerfeind \& Fischer (2005) independently manipulated larval density and food availability in Bicyclus anynana (Butler). According to their results, high larval density on its own shortened the larval development period, but larval food stress prolonged it.

The shorter larval development period of males compared to females was observed at all densities tested. The faster growth of males, which is common in insects, is generally attributed to selection for protandry in males to maximize the number of matings and females to minimize pre-reproductive period (Fagerström \& Wiklund, 1982). In the present study, however, males had a similar developmental strategy as indicated by the insignificant rela- tionship between sex and density and the length of the developmental period. Therefore, the stronger selection for males to have a shorter development may be explained partly by the growth patterns of the females. It may be an adaptation to the short adult lifespan of this insect. Babilis \& Mazomenos (1992) found that mating in $S$. nonagrioides started at the first scotophase following emergence, and mated females did not mate again, whereas a few males mated more than once.

Although high density lowered pupal weight in both sexes, males appeared to achieve a certain weight by prolonging the period they spent in the larval stage (Fig. 2). Furthermore, food availability significantly affects developmental time but not weight in males. This suggests that small size may not be as costly for the fitness of males, as it is for females; it also suggests that a large size is not advantageous for males. Female weight correlated positively with increase in food availability, indicating that female growth is more sensitive to density. This differential response in the weight gain of males and females in response to crowding suggests that females are more susceptible than males to the availability of food that can be used to accumulate reserves. Food shortage is therefore a more serious issue for females because it reduces fecundity, and there appears to be a strong selection for increased fecundity. These differences also reflect insect ecology. Females are very sedentary: they do not fly before mating and mate near where they emerged (Lopez et al., 2003). Therefore, there is no opportunity for females to accumulate extra reserves for reproduction and their fecundity depends largely on food accumulated during larval development.

Our data differ from those of a previous study (Fantinou \& Tsitsipis, 1999), in which crowded larvae showed shorter developmental periods compared to those reared at low densities. In both studies, the different density groups were reared in boxes of same volume. In the previous study, however, the quantity of food far exceeded what could be consumed by the larvae and was replaced every two days. The different results in the two studies suggest that larvae exhibit developmental plasticity. It seems that competition for space does not prevent larvae from making full use of the reserves to attain the critical weight for metamorphosis by further increasing their developmental time when food is unlimited. It is also possible that, larval crowding, combined with low food availability, affects life history traits differently. During larval development we did not adjust the food level with respect to increasing larval mass. Since increase in density decreased the per capita availability of food, there were periods of food shortage when the larvae were in the last instar and probably had the highest consumption rate. Therefore, the influence of this density-dependent factor is likely to have increased as food was consumed and the larvae increased in size. Several authors have analysed plasticity in body size and generated predictions regarding optimal reaction norms of the age and size at maturity under differing environmental conditions (Nylin et al., 1996; Tenhumberg et al., 2000; Day \& Rowe, 
2002). According to Day \& Rowe (2002) they respond differently if the changes in resource levels occur before or after a developmental threshold for moulting to the next stage. Pre-threshold manipulations result in earlier metamorphosis and larger size, whereas post-threshold manipulations result in tradeoffs between growth and development. Further research is needed to understand fully the physiological mechanism underlying the specific threshold in this species.

High fecundity was associated with low larval crowding levels. In addition there was an effect of crowding on female lifespan, indicating that adults developing from crowded larvae have less time for oviposition. The correlations between adult life span, weight and fecundity do not indicate a differential allocation of energy between adult survival and reproduction but that the total amount of larval reserves determines potential fecundity. Thus, it seems that crowded larvae, although they may extend their development in order to reach a higher pupal weight, may not be able to invest more in reproduction. This could be related to physiological constraints that affect the allocation of reserves carried over from the larval stage into to adulthood (Moreau et al., 2006). It may also be associated with the reduced availability of food at high densities. Therefore, even though the quantity of food is sufficient for larval survival and development, female fecundity is also determined by the quality of the nutritional reserves carried over from the larval stage. However, fecundity in Mamestra brassicae L. is unaffected by larval rearing density (Kazimírová, 1996). Similarly, Javois et al. (2005) found no clear effect of larval density on oviposition in Yponomeuta evonymellus L., a constraint that may be related to difficulties in possessing adult "memory" of the larval stage during metamorphosis in holometabolous insects.

The logistic relationship, between larval food availability and fecundity per female, plateaus at high levels of larval food availability (Fig. 5) (Gotthard et al., 2007). Thus, increasing food availability does not result in females that are more fecund. It seems that the negative correlation between larval development and pupal weight also prevails when food is abundant. This may be how insects achieve a larger size and thereby produce more offspring, and still keep within the time constraints imposed by seasonality or time available for exploiting a habitat etc.

Our results show that the restriction in the availability of food when crowded during larval developmental may determine population life history traits. Further work is needed to clarify the differences in fitness of both sexes, as well as quantify the relationships among larval crowding, adult size, mating and reproductive ability.

ACKNOWLEDGEMENTS. We offer special thanks to T. Tammaru and the anonymous reviewers for their comments and constructive criticism that significantly improved this manuscript. Thanks are also due to Y. Symillides for advice and statistical help.

\section{REFERENCES}

Agnew P., Hide M., Sidobre C. \& Michalakis Y. 2002: A minimalist approach to the effects of density-dependent competition on insect life-history traits. Ecol. Entomol. 27: 396-402.

Al Salti M.N. 1984: Influence de la temperature pendant la vie imaginale sur les potentialités reproductrices de l'espèce Sesamia nonagrioides Levèbvre (Lep., Noctuidae). Acta Oecol. 5: 103-112.

AmEZAGA I. \& GARBISU C. 2000: Effect of intraspecific competition of progeny production of Tomicus piniperda (Coleoptera: Scolytidae. Environ. Entomol. 29: 1011-1017.

Babilis N. \& Mazomenos B.E. 1992: Pheromone production in Sesamia nonagrioides: diel periodicity and effect of age and mating. J. Insect Physiol. 38: 561-564.

BANIABASSI N. 1981: News. International Society of Sugar-cane Technologists. Entomol. Newsletters 10: 2.

Barbosa P. \& Peters T.M. 1970: The manifestations of overcrowding. Bull. Entomol. Soc. Am. 16: 89-93.

BAUERFEIND S.S. \& Fischer K. 2005: Effects of food stress and density in different life stages on reproduction in a butterfly. Oikos 111: 514-524.

Boggs C.L. 1997: Reproductive allocation from reserves and income in butterfly species with differing adult diets. Ecology 78: $181-191$.

BRAdSHAW W.E. \& Holzapfel C.M. 1989: Life-historical consequences of density-dependent selection in the pitcher-plant mosquito, Wyeomyia smithii. Am. Nat. 133: 869-887.

Butron A., Malvar R.A., Cartea M.E., Ordas A. \& Velasco P. 1999: Resistance of maize inbreds to pink stem borer. Crop Prot. 39: 102-107.

Cordero A., Malvar R.A., Butron A., Revilla P., Velasco P. \& Ordas A. 1998: Population dynamics and life-cycle of corn borers in south Atlantic European coast. Maydica 43: 5-12.

DenNo R.F. \& RoDerick G.K. 1992: Density-related dispersal in planthoppers: effects of interspecific crowding. Ecology 73: 1323-1334.

Denno R.F, McCluRe M.S. \& Ott J.R. 1995: Interspecific interactions in phytophagous insects: competition revisited and resurrected. Annu. Rev. Entomol. 40: 297-331.

DAY T. \& Rowe E.L. 2002: Developmental thresholds and the evolution of reaction norms for age and size at life history transitions. Am. Nat. 159: 338-350.

Eizaguirre M., Lopez C. \& Albajaes R. 2004: Dispersal capacity in the Mediterranean corn borer, Sesamia nonagrioides. Entomol. Exp. Appl. 113: 25-34.

FAgERStrom T. \& WiKLUND C. 1982: Why do males emerge before females? Protandry as a mating strategy in male and female butterflies. Oecologia 52: 164-166.

FAnTINOU A.A. \& TsitsipIS J.A. 1999: Effect of larval density on development and diapause of Sesamia nonagrioides (Lef.) (Lep., Noctuidae) under laboratory conditions. J. Appl. Entomol. 123: 187-190.

Fantinou A.A., Karandinos M.G. \& TsitsipIS J.A. 1995: Diapause induction in the Sesamia nonagrioides (Lepidoptera: Noctuidae) effect of photoperiod and temperature. Environ. Entomol. 24: 1458-1466.

Fantinou A.A., Tsitsipis J.A. \& Karandinos M.G. 1998: Diapause termination in Sesamia nonagrioides (Lepidoptera: Noctuidae) under laboratory and field conditions. Environ. Entomol. 27: 53-58.

Fantinou A.A., Perdikis D.C. \& Zota K. 2004: Reproductive responses to photoperiod and temperature by diapausing and non-diapausing populations of Sesamia nonagrioides Lef. (Lepidoptera - Noctuidae). Physiol. Entomol. 29: 169-175. 
Fischer K. \& FiedLer K. 2001: Effects of larval starvation on adult life-history traits in the butterfly species Lycaena tityrus (Lepidoptera: Lycaenidae). Entomol. Gener. 25: 249-254.

Gotthard K., Berger D. \& Walters R.J. 2007: What keeps insects small? Time limitation during oviposition diminishes the fecundity benefit of female size in a butterfly. Am. Nat. 169: 768-779.

Gibbs M., Lace L.A, Jones M.J. \& Moore A.J. 2004: Intraspecific competition in the speckled wood butterfly: Pararge aegeria effect of rearing density and gender on larval life history: J. Insect Sci. 4: 1-6.

Gillyboeuf N., Angade P., Lavenseau L. \& Peypelut L. 1994: Cold hardiness and overwintering strategy of the pink maize stalk borer Sesamia nonagrioides (Lepidoptera, Noctuidae). Oecologia 99: 366-373.

HirschBerger P. 1999: Larval population density affects female weight and fecundity in the dung beetle Aphodius ater. Ecol. Entomol. 24: 316-322.

HoNĚK A. 1993: Intraspecific variation in body size and fecundity in insects - a general relationship. Oikos 66: 482-493.

JavoIS J., TAMMARU T. \& KaAR M. 2004: Oviposition in an eruptive moth species, Yponomeuta evonymellus, is insensitive to the population density experienced during the larval period. Entomol. Exp. Appl. 115: 379-386.

Jones R.E., Hart J.R. \& Bull G.D. 1982: Temperature, size and egg production in the cabbage butterfly Pieris rapae L. Aust. J. Zool. 30: 223-232.

KAZIMírovÁ M. 1996: Influence of larval crowding and mating on lifespan and fecundity of Mamestra brassicae (Lepidoptera: Noctuidae). Eur. J. Entomol. 93: 45-52.

KLOMP H. 1964: Intraspecific competition and the regulation of insect numbers. Annu. Rev. Entomol. 9: 17-40.

LEONARD D.E. 1968: Effects of density of larvae on the biology of the gypsy moth, Porthetria dispar. Entomol. Exp. Appl. 11: 291-304.

López C., Eizaguirre M. \& Albajes R. 2003: Courtship and mating behaviour of the Mediterranean corn borer, Sesamia nonagrioides (Lepidoptera: Noctuidae). Spanish J. Agr. Res. 1: 43-51

Marshall L.D. 1990: Intraspecific variation in reproductive effort by female Parapediasia teterrella (Lepidoptera: Pyralidae) and its relation to body size. Can. J. Zool. 68: 44-48.

Mercer D.R. 1999: Effects of larval density on the size of Aedes polynesiensis adults (Diptera: Culicidae). J. Med. Entomol. 36: 702-708.

Moreau J., Benrey B. \& Thiery D. 2006: Grape variety affects larval performance and also female reproductive performance of the European grapevine moth Lobesia botrana (Lepidoptera: Tortricidae). Bul. Entomol. Res. 96: 205-212.

MuelLer L.D. 1997: Theoretical and empirical examination of density dependent selection. Annu. Rev. Ecol. Syst. 28: 269-288.

Nylin S., GotThard K. \& WikLund C. 1996: Reaction norms for age and size at maturity in Lasiommata butterflies: Predictions and tests. Evolution 50: 1351-1358.

Peters T.M. \& Barbosa P. 1977: Influence of population density on size, fecundity, and developmental rate of insects in culture. Annu. Rev. Entomol. 22: 431-450.

Quiring D.T. \& McNeIL J.N. 1984: Influence of intraspecific larval competition and mating on the longevity and reproductive performance of females of the leaf miner Agromyza frontella (Rondani) (Diptera: Agromyzidae). Can. J. Zool. 62: 2197-2200.

Rhainds M., Gries G., Ho C.T. \& Chew P.S. 2002: Dispersal by bagworm larvae, Metisa plana: effects of population density, larval sex, and host plant attributes. Ecol. Entomol. 27: 204-212.

Shafier M., Moczek A.P. \& NiJhout H.F. 2001: Food availability controls the onset of metamorphosis in the dung beetle Onthophagus taurus (Coleoptera: Scarabaeidae). Physiol. Entomol. 26: $173-180$

SAS Institute Inc. 2005: JMP A Guide to Statistical and Data Analysis. Version 4.0.2. SAS Institute, Inc., Cary, N.C.

Tammaru T., Kaitaniemi P. \& Ruohomaki K. 1996: Realized fecundity in Epirrita autumnata (Lepidoptera: Geometridae): relation to body size and consequences to population dynamics. Oikos 77: 407-416.

Tammaru T., Ruohomaki K. \& Montola M. 2000: Crowdinginduced plasticity in Epirrita autumnata (Lepidoptera: Geometridae): weak evidence of specific modifications in reaction norms. Oikos 90: 171-181.

Tenhumberg B., Tyre D. \& Roitberg B. 2000: Stochastic variation in food availability influences weight and age at maturity. J. Theor. Biol. 202: 257-272.

TsITSIPIS J.A. 1984: Rearing the corn borer Sesamia nonagrioides on artificial media in the laboratory. (Abstract.) In: Proceedings XVII International Congress of Entomology, 16-26 August, Hamburg. p. 316.

TsITSIPIS J.A. 1990: Contribution toward the development of an integrated control method for the corn stalk borer Sesamia nonagrioides (Lef.). In Casida J.E. (ed.): Pesticides and Alternatives. Elsevier, Amsterdam, pp. 217-228.

Received December 21, 2008; revised and accepted May 29, 2008 